\title{
Estado actual de las aplicaciones del ADN libre de célula circulante
}

\author{
Current status of circulating cell-free DNA applications
}

Wendy V. Jaraba-Álvarez Biol', Isaura P. Torres-Gómez PhD², Rubén D. Manrique-Hernández PhD ${ }^{3}$, Juan E. Gallo-Bonilla $P h D^{4}$

Resumen: el diagnóstico y tamizaje prenatal, así como el diagnóstico y seguimiento de enfermedades en diversos campos de la medicina, se hace, en la actualidad, de manera más sencilla gracias al ADN libre en plasma. Este ADN representa una pequeña parte de la información genética de un tejido en particular o, en el caso de las mujeres en embarazo, una proporción del ADN fetal. En la oncología, por ejemplo, dada la heterogeneidad del cáncer, la aplicación del ADN libre en plasma ha sido difícil de implementar ya que solo existen algunos biomarcadores tumorales específicos para su uso en investigación. Metodologías como la reacción en cadena de la polimerasa (PCR) en tiempo real muestran una gran sensibilidad para detectar mutaciones que permitan establecer un correcto dignóstico y tratamiento de algunas enfermedades como las fetales o las tumorales, al mismo tiempo que disminuye costos. Lo anterior, no deja de ser una gran oportunidad para continuar los procesos de investigación y desarrollo de pruebas que permitan, en un futuro cercano, implementar el uso del ADN libre de células en el área clínica, con resultados confiables en el diagnóstico y tratamiento de enfermedades sin poner en riesgo la integridad del paciente.

Palabras clave: ADN libre de células, biopsia líquida, diagnóstico prenatal, cáncer, aneuploidía.

Jaraba-Álvarez WV, Torres-Gómez IP, Manrique-Hernández RD, Gallo-Bonilla JE. Estado actual de las aplicaciones del ADN libre de célula circulante. Medicina \& Laboratorio 2017; 23: 551-564.

${ }^{1}$ Bióloga. Investigadora, Genoma CES, Universidad CES. Medellín, Colombia. Correspondencia: Calle 58 \# 50C - 02.

Sexto piso, Laboratorio GenomaCES, Clínica CES. Barrio Prado Centro. Correo electrónico: wjaraba@ces.edu.co

${ }^{2}$ Bacterióloga, MSc y PhD en Biología. Coodinadora de Laboratorio, GenomaCES, Universidad CES. Medellín, Colombia.

${ }^{3}$ Químico Farmacéutico, Especialista, MSc y PhD en Epidemiología. Director de Investigación e Innovación, Universidad CES. Medellín, Colombia.

${ }^{4}$ Biotécnologo, Biológo Molecular y Microbiólogo, PhD en Ciencias Biomédicas. Director Científico, GenomaCES, Universidad CES. Medellín, Colombia.

Conflicto de intereses: Ios autores declaran que no tienen conflictos de intereses 
D urante años se han realizado esfuerzos científicos dirigidos al desarrollo de pruebas para el diagnóstico y seguimiento de enfermedades que sean lo menos invasivas para el paciente. Entre estos, la detección del cáncer y el tamizaje prenatal son las áreas diagnósticas en las que más se ha perseguido este objetivo. Desde hace cerca de setenta años se conoce de la existencia en plasma del ADN libre de célula (cfDNA, del inglés, cell free DNA) [1] y, desde entonces, se ha estudiado y caracterizado este material genético. En el caso del cáncer, en 1989 se reportó el hallazgo de alteraciones específicas en el ADN libre de célula [2], que soportaba su utilidad en el diagnóstico y tratamiento de esta enfermedad.

Por otro lado, desde los años ochenta, los niveles de analitos como la fentoproteína alfa, la gonadotropina coriónica humana, el estriol sin conjugar, la inhibina A y la proteína A plasmática asociada al embarazo (PAPP-A), existentes en el plasma materno, se postulaban como herramientas para el tamizaje de aneuploidías durante el embarazo [3]. Fue solo hasta 1997 que se observó que existía cierta cantidad de ADN «fetal» en el plasma materno, al encontrar fragmentos del cromosoma $Y$ en mujeres embarazadas de fetos de género masculino [4]. Gracias a estos estudios, se dispone, en la actualidad, de una nueva manera de desarrollar pruebas mínimamente invasivas y altamente sensibles con aplicaciones en estos dos campos de la medicina.

Se cree que una de las principales fuentes de ADN libre de célula es la liberación celular activa de ADN recién sintetizado, probablemente en asociación con complejos de proteínas de membrana móviles, de forma homeostática [5]. Otras fuentes menores incluyen la lisis celular por vía necrótica, la apoptosis, la liberación espontánea de ácidos nucleicos recién sintetizados y la descomposición de células sanguíneas. Este ADN libre de célula también puede ingresar en las células somáticas por la asociación con las proteínas transmembranales, y mostrar actividad biológica que podría estar relacionada con las metástasis [6,7]. Varios estudios han demostrado una elevación de los niveles de ADN libre de célula en pacientes con cáncer $[8,9]$, pero esta única característica no se puede tomar como método de diagnóstico definitivo, ya que se ha observado que existen muchas otras condiciones que elevan su cantidad en plasma, como el embarazo, la obesidad, el ejercicio, la inflamación, entre otros [10]. Para el mejor entendimiento del papel biológico y diagnóstico del ADN libre de célula la ciencia avanza en el desarrollo de métodos moleculares que faciliten la detección y caracterización de estas moléculas. Es así como los conceptos de «biopsia líquida» y "diagnóstico prenatal no invasivo» serán desarrollados en este escrito, para describir el estado actual de las aplicaciones del ADN libre de célula.

\section{Aplicación del ADN libre de célula en el diagnóstico del cáncer: biopsia líquida}

El cáncer es una enfermedad ampliamente variable que puede ser causada por cambios en genes puntuales, o en una colección de los mismos. Su diagnóstico se dificulta debido a que algunos tumores pueden ser asintomáticos en etapas tempranas, además de los costos elevados de las pruebas, lo que obstaculiza el acceso a las mismas. Por otro lado, es difícil monitorear el progreso de un tratamiento debido a las altas tasas mutacionales de las células tumorales $y$, en muchos de los casos, solo se logra ob- 
tener una muestra para análisis por medio de una biopsia, pero en otros de ellos, dependiendo de la ubicación del tumor, recolectar este tipo de muestras puede ser muy complejo [11].

Es así como surge la necesidad de usar otro tipo de muestras para el diagnóstico y monitoreo del cáncer, como el ADN libre de célula, el cual parte de la teoría de que algunas células tumorales pueden liberar al torrente sanguíneo ADN tumoral (ctDNA, del inglés circulating tumoral DNA) [12] por medio de los mecanismos ya mencionados, lo que posibilita obtener una «biopsia» de las células tumorales, prácticamente, en tiempo real [13]. De allí se deriva el término «biopsia líquida». En esta biopsia, obtenida comúnmente de sangre periférica, también se pueden hallar algunas células tumorales circulantes (CTC, del inglés, Circulating Tumoral Cells) que se desprenden de algunos tumores y que, igualmente, pueden ser utilizadas para el estudio tumoral $[14,15]$. No obstante, algunos estudios han demostrado que el ADN libre de célula, combinado con la búsqueda de mutaciones específicas del tumor esperado, resulta ser un mejor marcador para el pronóstico del paciente en comparación con el estudio de las células tumorales circulantes [16].

Uno de los primeros acercamientos hacia el uso de la biopsia líquida en el diagnóstico del cáncer surgió de una simple cuantificación de las concentraciones de ADN libre de célula presente en el plasma, ya que varios estudios habían reportado una diferencia significativa entre la cantidad de este entre los pacientes sanos o con enfermedades benignas y aquellos con cáncer $[8,9]$. No obstante, el cáncer no es la única razón por la que se presentan concentraciones elevadas de ADN libre de célula en el plasma. Como se mencionó anteriormente, existen otros factores asociados a esto, por lo que se ha hecho necesario incluir métodos más específicos para el diagnóstico del cáncer, como la búsqueda de mutaciones asociadas al tipo de tumor esperado o metilaciones en genes específicos [17-20].

Por otro lado, dado que los tumores cuentan con gran heterogeneidad celular, además de una amplia variedad de mutaciones, que pueden ser diferentes entre los tumores principales y las metástasis [21], su tratamiento es complicado, especialmente cuando se basa en el resultado de una biopsia tomada de una única región tumoral, pues, en muchos casos, esta no refleja datos significativos sobre el tumor completo. Esta heterogeneidad puede ser evaluada, en menor o mayor escala, y de manera puntual o no, por medio del estudio del ADN libre de célula y diferentes métodos de secuenciación (véase figura 1), que analicen ya sea aberraciones en el número de copias (CNA, por sus siglas en inglés), variantes en un único nucleótido (SNV, por sus siglas en inglés) o hipometilación e hipermetilación de genes específicos [22-24].

Para la obtención del ADN libre de célula una muestra de sangre periférica es recolectada en tubos Streck y sometida a centrifugación, para separar el plasma de donde será obtenido por medio de un proceso de extracción. Posteriormente, el ADN libre de célula se cuantifica mediante reacción en cadena de la polimerasa (PCR, por sus siglas en inglés) cuantitativa y se buscan mutaciones específicas, al igual que hiper o hipometilaciones relacionadas con el tipo de cáncer específico que se sospecha. Estos resultados son empleados en las diferentes etapas de la clínica del paciente [25] (véase figura 1). 


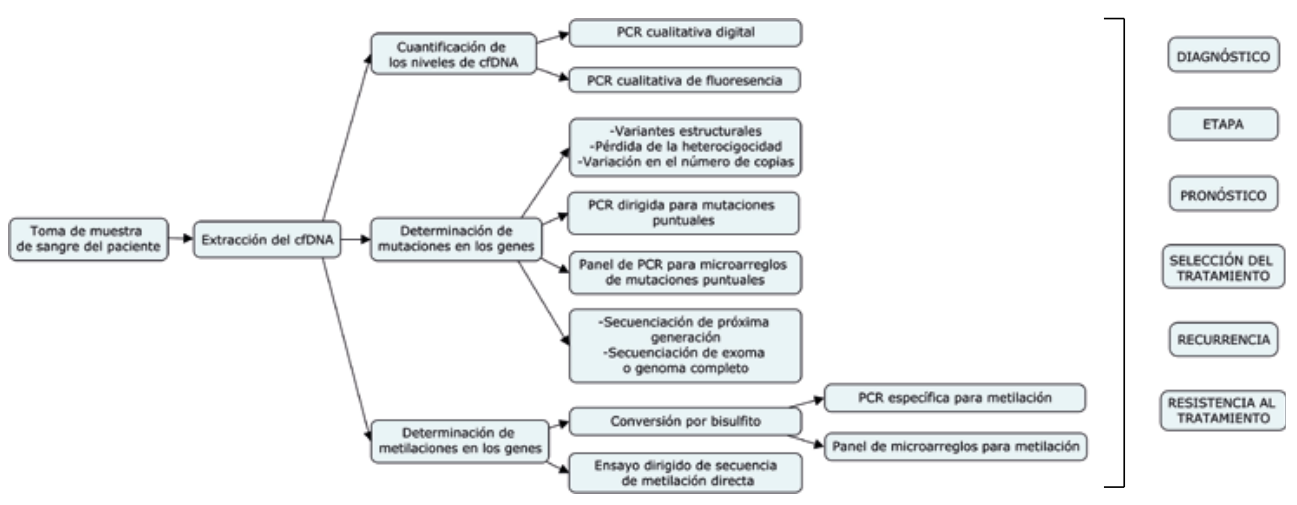

Figura 1. Obtención, análisis genético y uso clínico del ADN libre de célula. Tomada y modificada de "The clinical role of circulating free tumor DNA in gastrointestinal malignancy" por Howell y colaboradores, 2017, Trans/ Res, 183, p. 139. Copyright ${ }^{\circledR} 2016$ por Elsevier Inc. [25].

Hasta el momento, no hay un consenso de cómo se puede utilizar el ADN libre de célula para un diagnóstico definitivo del cáncer sin necesidad de una biopsia del tumor, pero sí se ha hecho un acercamiento hacia los biomarcadores asociados a la carcinogénesis temprana. En diferentes estudios de casos y controles se han encontrado, a través del estudio de ADN libre de células, mutaciones en el gen KRAS en pacientes con cáncer pancreático, las cuales no se observan en la población sana, con una sensibilidad del $27 \%$ y una especificidad del $100 \%[26,27]$. El aumento siginificativo de la sensibilidad se logra con el estudio adicional del marcador tumoral CA19-9, lo que hace que estos dos marcadores sean una buena herramienta para la detección temprana en este tipo de cáncer [28]. Resultados similares se han reportado para el cáncer colorrectal [26] y el melanoma [29].

Por otro lado, eventos epigenéticos como la metilación de las islas CpG ocurren en etapas tempranas del desarrollo de cáncer, lo que sugiere que la metilación del ADN puede ser otro biomarcador para el diagnóstico temprano [30]. Este evento de metilación ha sido observado en regiones génicas como GSTP1 [31,32], SEPT9 [33], RASSF1A $[34,35]$ y $B R C A[36]$, entre otros.

Los hallazgos obtenidos de la biopsia líquida permiten no solo obtener una visión en tiempo real de la genética del tumor, sino también hacer un seguimiento del mismo durante el tratamiento, siendo esta una de las aplicaciones más importantes, en especial cuando se enfocan en terapias para tumores con mecanismos conocidos de resistencia al tratamiento. La figura 2 ilustra un caso hipotético de cómo se puede aplicar esta estrategia, donde un primer curso de tratamiento se da al identificar las células tumorales en una biopsia y sus mutaciones específicas, pero a medida que este avanza se pueden generar cambios en las células tumorales que las hacen resistentes al primer tratamiento, al igual que la metástasis de estas células ya resistentes. En este punto es donde resulta mas relevante el análisis del ADN tumoral circulante, ya que, aunque una nueva biopsia puede ser viable de obtener, una muestra de sangre periférica es 


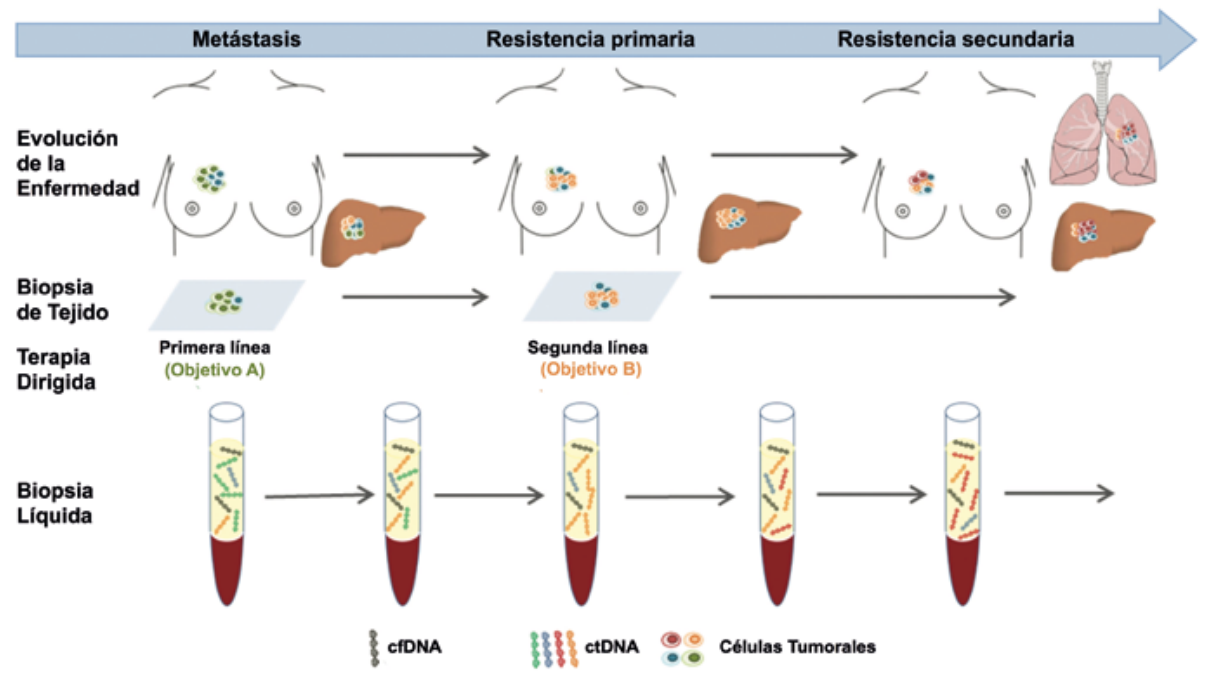

Figura 2. Biopsia líquida frente la biopsia de tejido para el monitoreo de la respuesta a la terapia y la resistencia a medicamentos. Escenario hipotético del curso de la enfermedad de un paciente con cáncer de mama metastático. La primera línea de tratamiento está basada en la biopsia del tumor primario donde cambios relevantes en la metástasis pueden pasar desapercibidos, llevando a una resistencia primaria. Luego de cambiar el tratamiento surge una resistencia secundaria. Cambios genéticos de clones resistentes pueden ser analizados utilizando una biopsia líquida, y así los mecanismos de resistencia pueden ser reconocidos antes de que la progresión sea clínicamente obvia. Tomada y modificada de "Circulating tumor DNA as a liquid biopsy for cáncer" por Heitzer y colaboradores, 2015, Clin Chem, 61, p. 113. Copyright ${ }^{\odot} 2014$ por American Association for Clinical Chemistry [37].

mucho menos invasiva, puede ser repetida varias veces a medida que avanza el tratamiento y provee la información necesaria para modificarlo y poder atacar estas nuevas células tumorales [37].

La figura 3 muestra que el ADN tumoral circulante también puede ser utilizado como un marcador de pronóstico o recurrencia después del tratamiento, mediante el monitoreo de sus niveles durante todo el curso de este. En tipos específicos de cáncer, como el colorrectal, se ha demostrado que cuando se encuentran niveles detectables de ADN libre de célula, luego de la cirugía para extracción del tumor se presenta, generalmente, recurrencia en menos de un año [38]. También se ha visto que las altas concentraciones de ADN libre de célula, junto con las mutaciones en el gen KRAS, son indicadores claros de un mal pronóstico en pacientes con cáncer colorrectal metastásico [39]; resultados similares se han observado en pacientes con cáncer de mama [40].

No todos los tipos de cáncer pueden ser monitoreados por medio de una biopsia líquida, como ocurre con los tumores endometriales, en los que el ADN libre de célula puede ser utilizado como un biomarcador para el pronóstico, pero no como una prueba para su detección debido a que los niveles de $A D N$ libre de célula no varían de manera significativa respecto a las personas sanas [41]. Por otro lado, varias iniciativas se han realizado para verificar en qué casos 

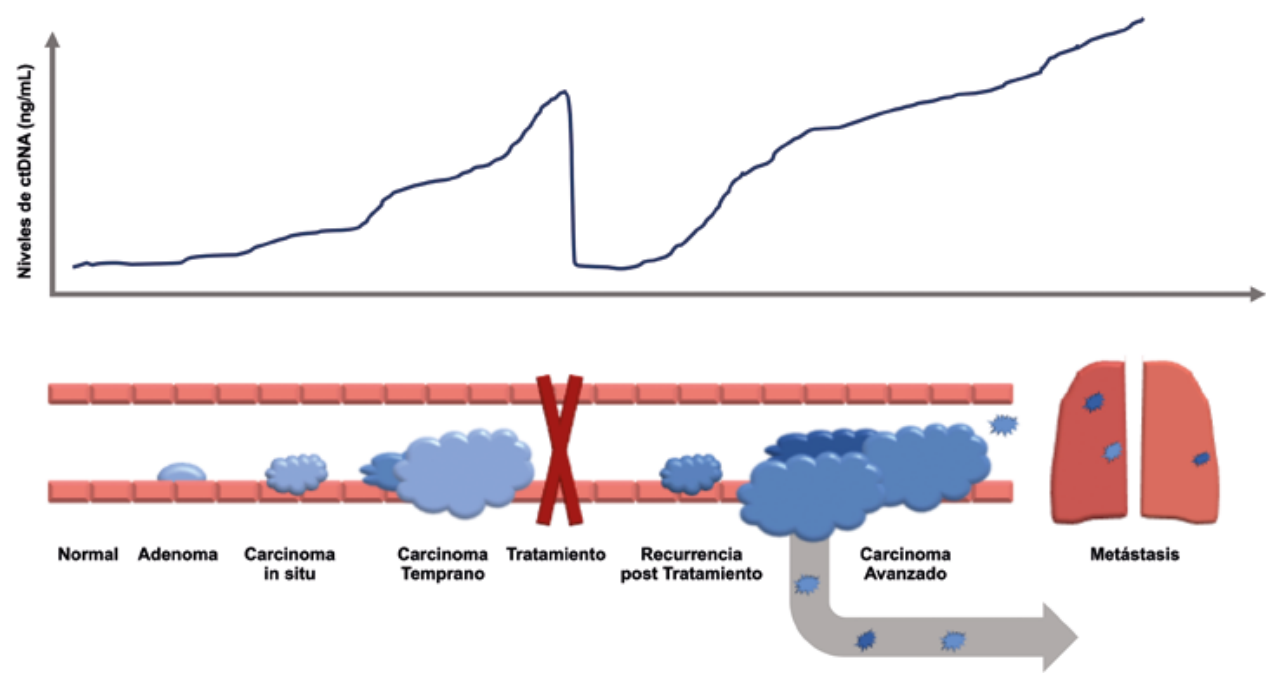

Figura 3. Desarrollo del cáncer y su relación con los niveles de ctDNA. En individuos sanos los niveles de ctDNA se mantienen bajos; ante la presencia de adenomas los niveles aumentan, lo hacen más con el desarrollo del carcinoma in situ y aún más con la progresión a cáncer temprano. El tratamiento causa un rápido descenso en los niveles de ctDNA, comparable con los de un individuo sano; sin embargo, los niveles de ctDNA son detectables en la recurrencia de la enfermedad postratamiento y aumentan rápidamente a medida que avanza el carcinoma y se desarrolla la metástasis. Tomada y modificada de "The clinical role of circulating free tumor DNA in gastrointestinal malignancy" por Howell y colaboradores, 2017, Trans/ Res, 183, p. 139. Copyright ${ }^{\circledR} 2016$ por Elsevier Inc. [25].

la biopsia líquida es una muy buena alternativa para ser aplicada como una herramienta para el diagnóstico o el seguimiento. La elevación del ADN libre de célula en plasma ha sido documentada o reportada en los casos de variación en los niveles de metilación o mutaciones puntuales para el cáncer de seno [42-45], colorrectal [20,4651], de pulmón [52-59] y de próstata [6066], los tumores cervicales [53,67-69], ováricos [70], de esófago $[71,72]$ y testiculares $[65,73]$, el carcinoma hepatocelular [74-76] y nasofaríngeo [77,78], la leucemia [79], el linfoma [80-82] y el melanoma $[83,84]$.

Otra posible fuente de ADN libre de célula, en lugar del plasma, es la orina, la cual se conoce desde hace mucho tiempo, pero cuyo uso clínico no ha sido ampliamente caracterizado. La orina es una sustancia muy compleja, por lo que puede ser una fuente de diferentes bimarcadores, desde proteínas hasta ácidos nucleicos [85]. EI ADN libre de células en orina (ucfDNA, del inglés, Urine cell free DNA) se origina a partir de células que entran en contacto directo con la orina o desde el ADN libre de célula presente en la sangre. Es por esto que el ADN libre de células en orina puede ser muy útil para la identificación de tipos de cáncer del tracto urinario [86]. Hasta el momento, todas las investigaciones publicadas en este tema han sido preliminares y en pequeños grupos de pacientes, aún muy alejado de una aplicación clínica concreta [87-93]. Un estudio publicado en 2008 demostró que, respecto a las muta- 
ciones del gen KRAS, el ADN libre de célula en orina podría ser mas representativo que el ADN libre de célula en plasma [94]. Estos resultados sugieren una alta sensibilidad de la prueba, aunque no confirman que pueda ser utilizada para diagnóstico debido a que fueron obtenidos en un grupo de pacientes muy pequeño.

Debido a la heterogeneidad del cáncer, la aplicación en clínica de la biopsia líquida ha sido difícil de implementar, por lo que es utilizada únicamente para algunos biomarcadores específicos, mientras que su uso pleno se restringe a la investigación. En este momento, los estudios se enfocan en hallar biomarcadores para pruebas cada vez más sensibles y específicas, que puedan, en un futuro cercano, ser utilizadas en el diagnóstico y seguimiento del cáncer, con resultados confiables, sin poner en riesgo la integridad del paciente.

\section{Diagnóstico prenatal no invasivo}

El diagnóstico prenatal se realiza ampliamente desde hace varias décadas, con técnicas bastante sensibles y eficientes, pero que generan un alto riesgo para el feto debido a la calidad invasiva de los métodos empleados para la toma de las muestras requeridas para su análisis. Estas técnicas son principalmente la amniocentesis y la biopsia de vellosidades coriónicas, las cuales pueden tener efectos adversos, donde la pérdida del embarazo es el peor de ellos. Es por esto que la búsqueda de pruebas menos invasivas es una necesidad apremiante [95].

Se cree que el ADN libre de célula obtenido de una mujer en embarazo proviene de la apoptosis de células del trofoblasto, por lo que muchos autores no utilizan el término ADN libre del "feto». Este ADN libre de célula está conformado por fragmentos muy pequeños (menos de 200 pares de bases) y puede ser detectado en el plasma materno a partir de las siete semanas, y desaparecer rápidamente después del parto $[96,97]$. En 1989, Lo y colaboradores [98] describieron por primera vez la técnica de determinación de sexo fetal por medio de una reacción en cadena de la polimerasa convencional, que permitió determinar el sexo de los fetos de 19 mujeres gestantes.

En 1997, del mismo grupo de investigación, reportaron que era posible encontrar ADN fetal en el plasma de la madre gestante, no solo de células específicas, como antes creían, sino como fragmentos del cromosoma $Y$ en pacientes gestantes con fetos masculinos [4]. En el año siguiente, por medio de la reacción en cadena de la polimerasa en tiempo real, lograron cuantificar el ADN fetal, el cual se encontró entre el 3,4\% y el $6,2 \%$ del total de ADN libre de célula obtenido de la madre [95]. Estudios posteriores demostraron que, en realidad, la concentración del ADN libre de célula que pertenece al feto representa entre el $10 \%$ y el $20 \%$ del ADN libre de célula total de la madre [99].

En 1999 se reportó, por primera vez, que era posible encontrar una relación entre la cantidad de ADN libre de célula de madres gestantes y la presencia de trisomía 21 en el feto, ya que existían valores más elevados en las madres gestantes cuando el feto tenía la aneuploidía en comparación con los controles de madres gestantes de fetos sin esta entidad clínica [100]. No obstante, este hallazgo no indica que pueda ser tomado como una herramienta para el diag- 
nóstico, ya que los niveles de ADN libre de célula se pueden ver afectados por varias razones y su variabilidad en las mujeres gestantes es muy alta, lo que no permite establecer un valor «normal» estándar que indique si hay o no una aneuploidía.

Debido a su condición no invasiva, el grupo de pruebas prenatales a partir de ADN libre de célula se conoce bajo las siglas NIPT (del inglés, Non invasive prenatal testing) y abarca la determinación del sexo fetal y el tamizaje prenatal de enfermedades genéticas. Las pruebas prenatales no invasivas se han usando en la clínica desde el 2011 [101] y han sido de gran utilidad para el diagnóstico de aneuploidías en mujeres embarazadas [102], con porcentajes de detección de más del 99\% y una tasa de falsos positivos menor al 0,1\% [103-105]. Estos resultados positivos han llevado a sociedades profesionales a ver los beneficios de las pruebas prenatales no invasivas para el diagnóstico de aneuploidías y recomendarlas para otro tipo de tamizajes después de la decima semana de embarazo [106].

Las técnicas moleculares utilizadas en las pruebas prenatales no invasivas pueden variar y, así mismo, su costo y accesibilidad. En el caso de las pruebas de determinación del sexo fetal se pueden emplear técnicas moleculares simples, como la reacción en cadena de la polimerasa en tiempo real para amplificar regiones del cromosoma $\mathrm{Y}$, que cuando ocurre se reporta como compatible con la gestación de un feto masculino, y ante su ausencia como la gestación de un feto de sexo femenino. A su vez, el diagnóstico de aneuploidías puede ser realizado con la misma técnica. En el caso de la trisomía 21 se puede cuantificar uno o varios genes encontrados en la región crítica, denomidada así por ser la causante del fenotipo, para revisar si hay un aumento indicativo de la existencia de una copia extra de estos genes blanco [107]. Por otro lado, esto también puede ser verificado por medio de técnicas de secuenciación de nueva generación, lo que le da una buena resolución a la prueba, pero aumenta los costos [108].

En cuanto al uso de estas pruebas en el diagnóstico de las enfermedades monogénicas se han hecho varias aproximaciones; no obstante, dado que estas enfermedades son causadas, usualmente, por cambios en uno o unos pocos nucleótidos del ADN fetal, su diagnóstico por medio de pruebas prenatales no invasivas se dificulta, pues, como se mencionó antes, el ADN fetal solo representa entre el $10 \%$ y el $20 \%$ del ADN libre de célula materno, por lo que se requieren de pruebas muy sensibles para su detección [109].

Hasta el momento se han utilizado, principalmente, dos métodos para el diagnóstico de estas enfermedades. El primero se basa en la búsqueda de mutaciones heredadas del padre que deben estar ausentes en el genoma materno. Para las enfermedades autosómicas dominantes el hecho de hallar la mutación en el ADN libre de célula materno indica que el feto tiene la enfermedad; esto se ha validado con éxito en los casos de acondroplasia $[110,111]$, distrofia miotónica [112] y enfermedad de Huntington [113]. En cuanto a las enfermedades autosómicas recesivas la ausencia del alelo paternal portador de la mutación indicaría que no hay riesgo de la enfermedad, lo que evita, así, la necesidad de métodos invasivos para su diagnóstico. Esto se ha aplicado para enfermedades como la $\beta$-talasemia [114,115], la fibrosis quística [116,117] y la hiperplasia adrenal congénita [118]. 
El segundo método utilizado se aplica cuando existen alelos compartidos de la madre y el padre, lo que requiere del uso de técnicas mas sensibles y específicas que permitan hacer una diferenciación entre los alelos maternos y los fetales para poder establecer el diagnóstico. En los casos en que ambos padres son portadores de alelos mutantes se puede utilizar una reacción en cadena de la polimerasa digital (similar a la convencional, pero con una sensibilidad mayor) y en los que solo la madre es portadora de la mutación una secuenciación masiva en paralelo [119]. Estas técnicas se han utilizado con éxito para la detección de mutaciones heredadas por la madre en los casos de $\beta$-talasemia [120], anemia falciforme [121], hemofilia [122] y acidemia metilmalónica [123].

A pesar de las grandes ventajas que ofrecen las pruebas prenatales no invasivas, es importante saber que tienen sus limitaciones. Es así como a toda mujer embarazada que se someta a este tipo de pruebas se le debe informar que los análisis basados en ADN libre de célula no reemplazan los métodos de diagnóstico invasivos ya conocidos, debido a la posibilidad de falsos positivos o negativos relacionados a la biología de este tipo de material genético. Es por esto que los resultados positivos obtenidos de una prueba prenatal no invasiva deben ser confirmados por los métodos invasivos convencionales antes de tomar cualquier decisión [124].

Los fragmentos de ADN del feto libres en el plasma se pueden ver influenciados por el estado cromosómico fetal [124127], la preeclampsia durante el embarazo [128], el estado de tabaquismo materno $[124,128]$ y algunos parámetros del primer trimestre del embarazo. El peso materno está entre uno de los mayores predictores del número de fragmentos de ADN fetal $[119,124,128]$, como se ve evidenciado en las altas tasas de errores y falsos negativos en embarazos de pacientes con obesidad $[129,130]$. Otros factores biológicos, como el mosaicismo placentario confinado [131,132], la presencia de un gemelo desaparecido durante el embarazo [133], las aberraciones genéticas en el genotipo materno [134,135] o la malignidad materna $[136,137]$ pueden afectar negativamente el rendimiento de las pruebas prenatales no invasivas.

\section{Conclusiones}

EI ADN libre de célula abre un campo de posibilidades en diferentes áreas de la medicina, lo que facilita la realización de pruebas mínimamente invasivas para el paciente, con una alta especificidad. Aún queda mucho camino por recorrer para la implementación en la práctica clínica de algunas pruebas; además, se deben siempre tener en cuenta las limitaciones del ADN libre de célula en algunas áreas. A pesar de esto, sigue siendo una muy buena alternativa en el diagnóstico y seguimiento del cáncer, y como un primer acercamiento para el tamizaje prenatal. El uso de ADN libre de célula puede bajar los costos de muchas de las pruebas realizadas, de acuerdo con el método de detección que se aplique, ya que se pueden emplear técnicas muy económicas como la reacción en cadena de la polimerasa en tiempo real, sin perjudicar la efectividad de la prueba. De esta manera, es necesario investigar e invertir en el desarrollo de nuevas pruebas y metodologías asociadas el ADN libre de célula para lograr bajar más sus costos y disponer de su aplicación en todos los campos de la medicina. 


\section{Bibliografía}

1. Mandel P, Metais P. Les acides nucléiques du plasma sanguin chez l'homme. C R Seances Soc Biol Fil 1948; 142: 241-243

2. Stroun $M$, Anker $P$, Maurice $P$, Lyautey J, Lederrey C, Beljanski M. Neoplastic characteristics of the DNA found in the plasma of cancer patients. Oncology 1989; 46: 318-322.

3. Saller DN, Jr., Canick JA. Current methods of prenatal screening for Down syndrome and other fetal abnormalities. Clin Obstet Gynecol 2008; 51: 24-36.

4. Lo YM, Corbetta N, Chamberlain PF, Rai V, Sargent IL, Redman CW, et al. Presence of fetal DNA in materna plasma and serum. Lancet 1997; 350: 485-487.

5. Bronkhorst AJ, Wentzel JF, Aucamp J, van Dyk E, du Plessis L, Pretorius PJ. Characterization of the cell-free DNA released by cultured cancer cells. Biochim Biophys Acta 2016; 1863: 157-165.

6. Agostini M, Enzo MV, Bedin C, Belardinelli V, Goldin E, Del Bianco P, et al. Circulating cell-free DNA: a promising marker of regional lymphonode metastasis in breast cancer patients. Cancer Biomark 2012; 11: 8998.

7. Gahan PB, Swaminathan R. Circulating nucleic acids in plasma and serum. Recent developments. Ann N Y Acad Sci 2008; 1137: 1-6.

8. Sozzi G, Conte D, Leon M, Ciricione R, Roz L, Ratcliffe $C$, et al. Quantification of free circulating DNA as a diagnostic marker in lung cancer. J Clin Oncol 2003; 21 : 3902-3908.

9. Kim K, Shin DG, Park MK, Baik SH, Kim TH, Kim S, et al. Circulating cell-free DNA as a promising biomarker in patients with gastric cancer: diagnostic validity and significant reduction of cfDNA after surgical resection. Ann Surg Treat Res 2014; 86: 136-142.

10. Gahan PB. Circulating Nucleic Acids in Early Diagnosis, Prognosis and Treatment Monitoring: An Introduction. Dordrecht, Paises Bajos: Spinger; 2015.

11. University of Pittsburgh. Neurological surgery. Types of Brain Tumors. 2017. Disponible: http://www.neurosurgery.pitt.edu/centers-excellence/neurosurgical-oncology/brain-and-brain-tumors/types-brain-tumors.

12. Schwarzenbach $\mathrm{H}$, Hoon DS, Pantel K. Cell-free nucleic acids as biomarkers in cancer patients. Nat Rev Cancer 2011; 11: 426-437.

13. Kuo YB, Chen JS, Fan CW, Li YS, Chan EC. Comparison of KRAS mutation analysis of primary tumors and matched circulating cell-free DNA in plasmas of patients with colorectal cancer. Clin Chim Acta 2014; 433: 284289.

14. Kim MY, Oskarsson T, Acharyya S, Nguyen DX, Zhang $\mathrm{XH}$, Norton L, et al. Tumor self-seeding by circulating cancer cells. Cell 2009; 139: 1315-1326.

15. Alix-Panabieres C, Pantel K. Circulating tumor cells: liquid biopsy of cancer. Clin Chem 2013; 59: 110-118.

16. Bidard FC, Madic J, Mariani P, Piperno-Neumann S, Rampanou A, Servois V, et al. Detection rate and prognostic value of circulating tumor cells and circulating tumor DNA in metastatic uveal melanoma. Int J Cancer 2014; 134: 1207-1213.

17. Chen X, Bonnefoi H, Diebold-Berger S, Lyautey J, Lederrey C, Faltin-Traub E, et al. Detecting tumor-related alterations in plasma or serum DNA of patients diagnosed with breast cancer. Clin Cancer Res 1999; 5: 22972303.

18. Sozzi G, Conte D, Mariani L, Lo Vullo S, Roz L, Lombardo $C$, et al. Analysis of circulating tumor DNA in plasma at diagnosis and during follow-up of lung cancer patients. Cancer Res 2001; 61: 4675-4678.

19. Madhavan $D$, Wallwiener $M$, Bents $K$, Zucknick $M$, Nees J, Schott S, et al. Plasma DNA integrity as a biomarker for primary and metastatic breast cancer and potential marker for early diagnosis. Breast Cancer Res Treat 2014; 146: 163-174.

20. Frattini M, Gallino G, Signoroni S, Balestra D, Lusa L, Battaglia L, et al. Quantitative and qualitative characterization of plasma DNA identifies primary and recurrent colorectal cancer. Cancer Lett 2008; 263: 170181.

21. Gerlinger M, Rowan AJ, Horswell S, Math M, Larkin J, Endesfelder D, et al. Intratumor heterogeneity and branched evolution revealed by multiregion sequencing. N Engl J Med 2012; 366: 883-892.

22. Chan KC, Jiang P, Zheng YW, Liao GJ, Sun H, Wong J, et al. Cancer genome scanning in plasma: detection of tumor-associated copy number aberrations, single-nucleotide variants, and tumoral heterogeneity by massively parallel sequencing. Clin Chem 2013; 59: 211-224.

23. Chan KC, Jiang P, Chan CW, Sun K, Wong J, Hui EP, et al. Noninvasive detection of cancer-associated genome-wide hypomethylation and copy number aberrations by plasma DNA bisulfite sequencing. Proc Natl Acad Sci U S A 2013; 110: 18761-18768.

24. Leary RJ, Sausen M, Kinde I, Papadopoulos N, Carpten JD, Craig D, et al. Detection of chromosomal alterations in the circulation of cancer patients with whole-genome sequencing. Sci Transl Med 2012; 4: 162 ra154.

25. Howell JA, Khan SA, Knapp S, Thursz MR, Sharma R. The clinical role of circulating free tumor DNA in gastrointestinal malignancy. Transl Res 2017; 183: 137154.

26. Spindler KL, Pallisgaard N, Andersen RF, Brandslund I, Jakobsen A. Circulating free DNA as biomarker and source for mutation detection in metastatic colorectal cancer. PLoS One 2015; 10: e0108247.

27. Castells A, Puig P, Mora J, Boadas J, Boix L, Urgell E, et al. K-ras mutations in DNA extracted from the plasma of patients with pancreatic carcinoma: diagnostic utility and prognostic significance. J Clin Oncol 1999; 17: 578-584.

28. Dianxu F, Shengdao Z, Tianquan H, Yu J, Ruoqing L, Zurong $\mathrm{Y}$, et al. A prospective study of detection of pancreatic carcinoma by combined plasma K-ras mutations and serum CA19-9 analysis. Pancreas 2002; 25: 336-341.

29. Shinozaki M, O’Day SJ, Kitago M, Amersi F, Kuo C, Kim J, et al. Utility of circulating B-RAF DNA mutation 
in serum for monitoring melanoma patients receiving biochemotherapy. Clin Cancer Res 2007; 13: 20682074.

30. Egger G, Liang G, Aparicio A, Jones PA. Epigenetics in human disease and prospects for epigenetic therapy. Nature 2004; 429: 457-463.

31. Wu T, Giovannucci E, Welge J, Mallick P, Tang WY, Ho SM. Measurement of GSTP1 promoter methylation in body fluids may complement PSA screening: a metaanalysis. Br J Cancer 2011; 105: 65-73.

32. Dumache $R$, Puiu $M$, Motoc $M$, Vernic $C$, Dumitrascu V. Prostate cancer molecular detection in plasma samples by glutathione S-transferase P1 (GSTP1) methylation analysis. Clin Lab 2014; 60: 847-852.

33. Church TR, Wandell M, Lofton-Day C, Mongin SJ, Burger M, Payne SR, et al. Prospective evaluation of methylated SEPT9 in plasma for detection of asymptomatic colorectal cancer. Gut 2014; 63: 317-325.

34. Hoque MO, Feng $Q$, Toure P, Dem A, Critchlow CW, Hawes SE, et al. Detection of aberrant methylation of four genes in plasma DNA for the detection of breast cancer. J Clin Oncol 2006; 24: 4262-4269.

35. Skvortsova TE, Rykova EY, Tamkovich SN, Bryzgunova OE, Starikov AV, Kuznetsova NP, et al. Cell-free and cell-bound circulating DNA in breast tumours: DNA quantification and analysis of tumour-related gene methylation. Br J Cancer 2006; 94: 1492-1495.

36. Ibanez de Caceres I, Battagli C, Esteller M, Herman JG, Dulaimi E, Edelson MI, et al. Tumor cell-specific BRCA1 and RASSF1A hypermethylation in serum, plasma, and peritoneal fluid from ovarian cancer patients. Cancer Res 2004; 64: 6476-6481.

37. Heitzer E, Ulz P, Geigl JB. Circulating tumor DNA as a liquid biopsy for cancer. Clin Chem 2015; 61: 112-123.

38. Diehl F, Schmidt K, Choti MA, Romans K, Goodman $\mathrm{S}$, Li M, et al. Circulating mutant DNA to assess tumor dynamics. Nat Med 2008; 14: 985-990.

39. Spindler KL, Pallisgaard N, Vogelius I, Jakobsen A. Quantitative cell-free DNA, KRAS, and BRAF mutations in plasma from patients with metastatic colorectal cancer during treatment with cetuximab and irinotecan. Clin Cancer Res 2012; 18: 1177-1185.

40. Dawson SJ, Tsui DW, Murtaza M, Biggs H, Rueda OM, Chin SF, et al. Analysis of circulating tumor DNA to monitor metastatic breast cancer. N Engl J Med 2013; 368: 1199-1209.

41. Tanaka H, Tsuda H, Nishimura S, Nomura H, Kataoka $\mathrm{F}$, Chiyoda T, et al. Role of circulating free alu DNA in endometrial cancer. Int J Gynecol Cancer 2012; 22: 8286.

42. Catarino R, Ferreira MM, Rodrigues $H$, Coelho A, Nogal A, Sousa A, et al. Quantification of free circulating tumor DNA as a diagnostic marker for breast cancer. DNA Cell Biol 2008; 27: 415-421.

43. Hashad D, Sorour A, Ghazal A, Talaat I. Free circulating tumor DNA as a diagnostic marker for breast cancer. J Clin Lab Anal 2012; 26: 467-472.

44. Zanetti-Dallenbach RA, Schmid S, Wight E, Holzgreve W, Ladewing A, Hahn S, et al. Levels of circulating cell-free serum DNA in benign and malignant breast lesions. Int J Biol Markers 2007; 22: 95-99.

45. Zanetti-Dallenbach R, Wight E, Fan AX, Lapaire O, Hahn S, Holzgreve W, et al. Positive correlation of cellfree DNA in plasma/serum in patients with malignant and benign breast disease. Anticancer Res 2008; 28: 921-925.

46. Schwarzenbach H, StoehImacher J, Pantel K, Goekkurt E. Detection and monitoring of cell-free DNA in blood of patients with colorectal cancer. Ann N Y Acad Sci 2008; 1137: 190-196.

47. Schmidt K, Diehl F. A blood-based DNA test for colorectal cancer screening. Discov Med 2007; 7: 7-12.

48. Taback B, Saha S, Hoon DS. Comparative analysis of mesenteric and peripheral blood circulating tumor DNA in colorectal cancer patients. Ann N Y Acad Sci 2006; 1075: 197-203.

49. Flamini E, Mercatali L, Nanni O, Calistri D, Nunziatini R, Zoli W, et al. Free DNA and carcinoembryonic antigen serum levels: an important combination for diagnosis of colorectal cancer. Clin Cancer Res 2006; 12: 6985-6988.

50. Kin C, Kidess E, Poultsides GA, Visser BC, Jeffrey SS. Colorectal cancer diagnostics: biomarkers, cell-free DNA, circulating tumor cells and defining heterogeneous populations by single-cell analysis. Expert Rev Mol Diagn 2013; 13: 581-599.

51. da Silva Filho BF, Gurgel AP, Neto MA, de Azevedo DA, de Freitas AC, Silva Neto Jda C, et al. Circulating cellfree DNA in serum as a biomarker of colorectal cancer. J Clin Pathol 2013; 66: 775-778.

52. Cheng $C$, Omura-Minamisawa $M$, Kang $Y$, Hara $T$, Koike I, Inoue T. Quantification of circulating cell-free DNA in the plasma of cancer patients during radiation therapy. Cancer Sci 2009; 100: 303-309.

53. Xie GS, Hou AR, Li LY, Gao YN, Cheng SJ. Quantification of plasma DNA as a screening tool for lung cancer. Chin Med J (Engl) 2004; 117: 1485-1488.

54. Xue $X$, Zhu YM, Woll PJ. Circulating DNA and lung cancer. Ann N Y Acad Sci 2006; 1075: 154-164.

55. Yoon KA, Park S, Lee SH, Kim JH, Lee JS. Comparison of circulating plasma DNA levels between lung cancer patients and healthy controls. J Mol Diagn 2009; 11: 182-185.

56. van der Drift MA, Hol $B E$, Klaassen $C H$, Prinsen $C F$, van Aarssen YA, Donders R, et al. Circulating DNA is a noninvasive prognostic factor for survival in non-small cell lung cancer. Lung Cancer 2010; 68: 283-287.

57. Lee SM, Park JY, Kim DS. Methylation of TMEFF2 gene in tissue and serum DNA from patients with non-small cell lung cancer. Mol Cells 2012; 34: 171-176.

58. Board RE, Williams VS, Knight L, Shaw J, Greystoke A, Ranson M, et al. Isolation and extraction of circulating tumor DNA from patients with small cell lung cancer. Ann N Y Acad Sci 2008; 1137: 98-107.

59. Tamkovich SN, Litviakov NV, Bryzgunova OE, Dobrodeev AY, Rykova EY, Tuzikov SA, et al. Cell-surfacebound circulating DNA as a prognostic factor in lung cancer. Ann N Y Acad Sci 2008; 1137: 214-217.

60. Goessl C, Muller M, Straub B, Miller K. DNA altera- 
tions in body fluids as molecular tumor markers for urological malignancies. Eur Urol 2002; 41: 668-676.

61. Delgado PO, Alves BC, Gehrke Fde S, Kuniyoshi RK, Wroclavski ML, Del Giglio A, et al. Characterization of cell-free circulating DNA in plasma in patients with prostate cancer. Tumour Biol 2013; 34: 983-986.

62. Schwarzenbach $\mathrm{H}$, Alix-Panabieres $\mathrm{C}$, Muller I, Letang N, Vendrell JP, Rebillard X, et al. Cell-free tumor DNA in blood plasma as a marker for circulating tumor cells in prostate cancer. Clin Cancer Res 2009; 15: 10321038.

63. Sunami E, Shinozaki M, Higano CS, Wollman R, Dorff TB, Tucker SJ, et al. Multimarker circulating DNA assay for assessing blood of prostate cancer patients. Clin Chem 2009; 55: 559-567.

64. Bryzgunova OE, Morozkin ES, Yarmoschuk SV, Vlassov VV, Laktionov PP. Methylation-specific sequencing of GSTP1 gene promoter in circulating/extracellular DNA from blood and urine of healthy donors and prostate cancer patients. Ann N Y Acad Sci 2008; 1137: 222-225.

65. Ellinger J, Albers $\mathrm{P}$, Perabo FG, Muller SC, von Ruecker A, Bastian PJ. CpG island hypermethylation of cell-free circulating serum DNA in patients with testicular cancer. J Urol 2009; 182: 324-329.

66. Chun FK, Muller I, Lange I, Friedrich MG, Erbersdobler A, Karakiewicz PI, et al. Circulating tumour-associated plasma DNA represents an independent and informative predictor of prostate cancer. BJU Int 2006; 98: 544548.

67. Guan T, Guo XY, Ye CL, Jiang YH. [Analysis of circulating DNA level in the plasma of cervical cancer patients]. Nan Fang Yi Ke Da Xue Xue Bao 2008; 28: 1663-1664, 1667.

68. Widschwendter A, Ivarsson L, Blassnig A, Muller $\mathrm{HM}$, Fiegl $\mathbf{H}$, Wiedemair $\mathbf{A}$, et al. $\mathrm{CDH} 1$ and $\mathrm{CDH} 13$ methylation in serum is an independent prognostic marker in cervical cancer patients. Int J Cancer 2004; 109: 163-166.

69. Widschwendter A, Muller HM, Fiegl H, Ivarsson L, Wiedemair A, Muller-Holzner E, et al. DNA methylation in serum and tumors of cervical cancer patients. Clin Cancer Res 2004; 10: 565-571.

70. Zachariah RR, Schmid S, Buerki N, Radpour R, Holzgreve $\mathbf{W}$, Zhong $\mathbf{X}$. Levels of circulating cell-free nuclear and mitochondrial DNA in benign and malignant ovarian tumors. Obstet Gynecol 2008; 112: 843-850.

71. Tomita H, Ichikawa D, Sai S, Morimura R, Murayama $\mathrm{Y}$, Komatsu S, et al. [Quantification of circulating plasma DNA fragments as tumor markers in patients with esophageal and gastric cancer]. Gan To Kagaku Ryoho 2007; 34: 1908-1910.

72. Hoffmann AC, Vallbohmer D, Prenzel $K$, Metzger $R$, Heitmann M, Neiss S, et al. Methylated DAPK and APC promoter DNA detection in peripheral blood is significantly associated with apparent residual tumor and outcome. J Cancer Res Clin Oncol 2009; 135: 12311237.

73. Ellinger J, Albers P, Muller SC, von Ruecker A, Bastian PJ. Circulating mitochondrial DNA in the serum of patients with testicular germ cell cancer as a novel nonin- vasive diagnostic biomarker. BJU Int 2009; 104: 48-52.

74. Ren N, Ye QH, Qin LX, Zhang BH, Liu YK, Tang ZY. Circulating DNA level is negatively associated with the longterm survival of hepatocellular carcinoma patients. World J Gastroenterol 2006; 12: 3911-3914.

75. lizuka N, Sakaida I, Moribe T, Fujita N, Miura T, Stark $M$, et al. Elevated levels of circulating cell-free DNA in the blood of patients with hepatitis $C$ virus-associated hepatocellular carcinoma. Anticancer Res 2006; 26: 4713-4719.

76. Tangkijvanich $\mathrm{P}$, Hourpai N, Rattanatanyong P, Wisedopas N, Mahachai V, Mutirangura A. Serum LINE-1 hypomethylation as a potential prognostic marker for hepatocellular carcinoma. Clin Chim Acta 2007; 379: 127-133.

77. Chan KC, Leung SF, Yeung SW, Chan AT, Lo YM. Persistent aberrations in circulating DNA integrity after radiotherapy are associated with poor prognosis in nasopharyngeal carcinoma patients. Clin Cancer Res 2008; 14: 4141-4145.

78. Jiang WW, Zahurak M, Goldenberg D, Milman Y, Park HL, Westra WH, et al. Increased plasma DNA integrity index in head and neck cancer patients. Int J Cancer 2006; 119: 2673-2676.

79. Jiang Y, Pan SY, Xia WY, Chen D, Wang H, Zhang LX, et al. [Dynamic monitoring of plasma circulating DNA in patients with acute myeloid leukemia and its clinical significance]. Zhongguo Shi Yan Xue Ye Xue Za Zhi 2012; 20: 53-56.

80. Hohaus S, Giachelia M, Massini G, Mansueto G, Vannata B, Bozzoli V, et al. Cell-free circulating DNA in Hodgkin's and non-Hodgkin's lymphomas. Ann Oncol 2009; 20: 1408-1413.

81. Hosny G, Farahat N, Hainaut P. TP53 mutations in circulating free DNA from Egyptian patients with nonHodgkin's lymphoma. Cancer Lett 2009; 275: 234-239.

82. Mussolin L, Burnelli R, Pillon M, Carraro E, Farruggia P, Todesco A, et al. Plasma cell-free DNA in paediatric lymphomas. J Cancer 2013; 4: 323-329.

83. Daniotti M, Vallacchi V, Rivoltini L, Patuzzo R, Santinami $M$, Arienti $F$, et al. Detection of mutated BRAFV600E variant in circulating DNA of stage III-IV melanoma patients. Int J Cancer 2007; 120: 2439-2444.

84. Nakamoto $D$, Yamamoto $N$, Takagi R, Katakura A, Mizoe JE, Shibahara T. Detection of microsatellite alterations in plasma DNA of malignant mucosal melanoma using whole genome amplification. Bull Tokyo Dent Coll 2008; 49: 77-87.

85. Calistri D, Casadio V, Bravaccini S, Zoli W, Amadori D. Urinary biomarkers of non-muscle-invasive bladder cancer: current status and future potential. Expert Rev Anticancer Ther 2012; 12: 743-752.

86. Su YH, Wang M, Aiamkitsumrit B, Brenner DE, Block TM. Detection of a K-ras mutation in urine of patients with colorectal cancer. Cancer Biomark 2005; 1: 177182.

87. Szarvas T, Kovalszky I, Bedi K, Szendroi A, Majoros A, Riesz $P$, et al. Deletion analysis of tumor and urinary DNA to detect bladder cancer: urine supernatant versus urine sediment. Oncol Rep 2007; 18: 405-409. 
88. Chang HW, Tsui KH, Shen LC, Huang HW, Wang SN, Chang PL. Urinary cell-free DNA as a potential tumor marker for bladder cancer. Int J Biol Markers 2007; 22: 287-294.

89. Zancan M, Galdi F, Di Tonno F, Mazzariol C, Orlando C, Malentacchi F, et al. Evaluation of cell-free DNA in urine as a marker for bladder cancer diagnosis. Int J Biol Markers 2009; 24: 147-155.

90. Casadio V, Calistri D, Salvi S, Gunelli R, Carretta E, Amadori D, et al. Urine cell-free DNA integrity as a marker for early prostate cancer diagnosis: a pilot study. Biomed Res Int 2013; 2013: 270457.

91. Casadio V, Calistri D, Tebaldi M, Bravaccini S, Gunelli R, Martorana G, et al. Urine cell-free DNA integrity as a marker for early bladder cancer diagnosis: preliminary data. Urol Oncol 2013; 31: 1744-1750.

92. Salvi S, Gurioli G, Martignano F, Foca F, Gunelli R, Cicchetti G, et al. Urine Cell-Free DNA Integrity Analysis for Early Detection of Prostate Cancer Patients. Dis Markers 2015; 2015: 574120.

93. Song BP, Jain S, Lin SY, Chen Q, Block TM, Song W, et al. Detection of hypermethylated vimentin in urine of patients with colorectal cancer. J Mol Diagn 2012; 14: 112-119.

94. Su YH, Wang M, Brenner DE, Norton PA, Block TM. Detection of mutated K-ras DNA in urine, plasma, and serum of patients with colorectal carcinoma or adenomatous polyps. Ann N Y Acad Sci 2008; 1137: 197-206.

95. Lo YM, Tein MS, Lau TK, Haines CJ, Leung TN, Poon PM, et al. Quantitative analysis of fetal DNA in maternal plasma and serum: implications for noninvasive prenatal diagnosis. Am J Hum Genet 1998; 62: 768775.

96. Chan KC, Zhang J, Hui AB, Wong N, Lau TK, Leung TN, et al. Size distributions of maternal and fetal DNA in maternal plasma. Clin Chem 2004; 50: 88-92.

97. Lo YM, Zhang J, Leung TN, Lau TK, Chang AM, Hjelm NM. Rapid clearance of fetal DNA from maternal plasma. Am J Hum Genet 1999; 64: 218-224.

98. Lo YM, Patel P, Wainscoat JS, Sampietro M, Gillmer MD, Fleming KA. Prenatal sex determination by DNA amplification from maternal peripheral blood. Lancet 1989; 2: 1363-1365.

99. Lun FM, Chiu RW, Chan KC, Leung TY, Lau TK, Lo YM. Microfluidics digital PCR reveals a higher than expected fraction of fetal DNA in maternal plasma. Clin Chem 2008; 54: 1664-1672.

100. Lo YM, Lau TK, Zhang J, Leung TN, Chang AM, Hjelm NM, et al. Increased fetal DNA concentrations in the plasma of pregnant women carrying fetuses with trisomy 21. Clin Chem 1999; 45: 1747-1751.

101. Chiu RW, Akolekar R, Zheng YW, Leung TY, Sun H, Chan KC, et al. Non-invasive prenatal assessment of trisomy 21 by multiplexed maternal plasma DNA sequencing: large scale validity study. BMJ 2011; 342: c7401.

102. Allyse M, Minear MA, Berson E, Sridhar S, Rote M, Hung A, et al. Non-invasive prenatal testing: a review of international implementation and challenges. Int J Womens Health 2015; 7: 113-126.
103. Gil MM, Quezada MS, Revello R, Akolekar R, Nicolaides $\mathrm{KH}$. Analysis of cell-free DNA in maternal blood in screening for fetal aneuploidies: updated meta-analysis. Ultrasound Obstet Gynecol 2015; 45: 249-266.

104. Bianchi DW, Parker RL, Wentworth J, Madankumar R, Saffer C, Das AF, et al. DNA sequencing versus standard prenatal aneuploidy screening. N Engl J Med 2014; 370: 799-808.

105. Norton ME, Wapner RJ. Cell-free DNA Analysis for Noninvasive Examination of Trisomy. N Engl J Med 2015; 373: 2582.

106. Benn P, Borrell A, Chiu RW, Cuckle H, Dugoff L, Faas $B$, et al. Position statement from the Chromosome Abnormality Screening Committee on behalf of the Board of the International Society for Prenatal Diagnosis. Prenat Diagn 2015; 35: 725-734.

107. Jiang $X$, Liu C, Yu T, Zhang L, Meng $K$, Xing Z, et al. Genetic dissection of the Down syndrome critical region. Hum Mol Genet 2015; 24: 6540-6551.

108. Hahn S, Lapaire O, Tercanli S, Kolla V, Hosli I. Determination of fetal chromosome aberrations from fetal DNA in maternal blood: has the challenge finally been met? Expert Rev Mol Med 2011; 13: e16.

109. Chiu EKL, Hui WWI, Chiu RWK. cfDNA screening and diagnosis of monogenic disorders - where are we heading? Prenat Diagn 2018; 38: 52-58.

110. Li Y, Page-Christiaens GC, Gille JJ, Holzgreve W, Hahn S. Non-invasive prenatal detection of achondroplasia in size-fractionated cell-free DNA by MALDI-TOF MS assay. Prenat Diagn 2007; 27: 11-17.

111. Saito H, Sekizawa A, Morimoto T, Suzuki M, Yanaihara T. Prenatal DNA diagnosis of a single-gene disorder from maternal plasma. Lancet 2000; 356: 1170.

112. Amicucci P, Gennarelli M, Novelli G, Dallapiccola B. Prenatal diagnosis of myotonic dystrophy using fetal DNA obtained from maternal plasma. Clin Chem 2000; 46: 301-302.

113. Gonzalez-Gonzalez MC, Trujillo MJ, Rodriguez de Alba M, Garcia-Hoyos M, Lorda-Sanchez I, Diaz-Recasens J, et al. Huntington disease-unaffected fetus diagnosed from maternal plasma using QF-PCR. Prenat Diagn 2003; 23: 232-234.

114. Chiu RW, Lau TK, Leung TN, Chow KC, Chui DH, Lo YM. Prenatal exclusion of beta thalassaemia major by examination of maternal plasma. Lancet 2002; 360: 9981000.

115. Li Y, Di Naro E, Vitucci A, Zimmermann B, Holzgreve W, Hahn S. Detection of paternally inherited fetal point mutations for beta-thalassemia using size-fractionated cell-free DNA in maternal plasma. JAMA 2005; 293: 843-849.

116. Bustamante-Aragones A, Gallego-Merlo J, Trujillo-Tiebas MJ, de Alba MR, Gonzalez-Gonzalez C, Glover G, et al. New strategy for the prenatal detection/ exclusion of paternal cystic fibrosis mutations in maternal plasma. J Cyst Fibros 2008; 7: 505-510.

117. Gonzalez-Gonzalez MC, Garcia-Hoyos M, Trujillo MJ, Rodriguez de Alba M, Lorda-Sanchez I, Diaz-Recasens $\mathrm{J}$, et al. Prenatal detection of a cystic fibrosis mutation in fetal DNA from maternal plasma. Prenat Diagn 2002; 
22: 946-948.

118. Chiu RW, Lau TK, Cheung PT, Gong ZQ, Leung TN, Lo YM. Noninvasive prenatal exclusion of congenital adrenal hyperplasia by maternal plasma analysis: a feasibility study. Clin Chem 2002; 48: 778-780.

119. Hudecova I, Sahota D, Heung MM, Jin Y, Lee WS, Leung TY, et al. Maternal plasma fetal DNA fractions in pregnancies with low and high risks for fetal chromosomal aneuploidies. PLoS One 2014; 9: e88484.

120. Lun FM, Tsui NB, Chan KC, Leung TY, Lau TK, Charoenkwan $\mathrm{P}$, et al. Noninvasive prenatal diagnosis of monogenic diseases by digital size selection and relative mutation dosage on DNA in maternal plasma. Proc Natl Acad Sci U S A 2008; 105: 19920-19925.

121. Barrett AN, McDonnell TC, Chan KC, Chitty LS. Digital PCR analysis of maternal plasma for noninvasive detection of sickle cell anemia. Clin Chem 2012; 58: 1026-1032.

122. Tsui NB, Kadir RA, Chan KC, Chi C, Mellars G, Tuddenham EG, et al. Noninvasive prenatal diagnosis of hemophilia by microfluidics digital PCR analysis of maternal plasma DNA. Blood 2011; 117: 3684-3691.

123. Gu W, Koh W, Blumenfeld YJ, El-Sayed YY, Hudgins L, Hintz SR, et al. Noninvasive prenatal diagnosis in a fetus at risk for methylmalonic acidemia. Genet Med 2014; 16: 564-567.

124. Ashoor G, Syngelaki A, Poon LC, Rezende JC, Nicolaides $\mathrm{KH}$. Fetal fraction in maternal plasma cell-free DNA at 11-13 weeks' gestation: relation to maternal and fetal characteristics. Ultrasound Obstet Gynecol 2013; 41: 26-32.

125. Kinnings SL, Geis JA, Almasri E, Wang H, Guan X, McCullough RM, et al. Factors affecting levels of circulating cell-free fetal DNA in maternal plasma and their implications for noninvasive prenatal testing. Prenat Diagn 2015; 35: 816-822.

126. Rava RP, Srinivasan A, Sehnert AJ, Bianchi DW. Circulating fetal cell-free DNA fractions differ in autosomal aneuploidies and monosomy X. Clin Chem 2014; 60: 243-250.

127. Nicolaides KH, Syngelaki A, del Mar Gil M, Quezada MS, Zinevich Y. Prenatal detection of fetal triploidy from cell-free DNA testing in maternal blood. Fetal Diagn Ther 2014; 35: 212-217.
128. Poon LC, Musci T, Song K, Syngelaki A, Nicolaides KH. Maternal plasma cell-free fetal and maternal DNA at 11-13 weeks' gestation: relation to fetal and maternal characteristics and pregnancy outcomes. Fetal Diagn Ther 2013; 33: 215-223.

129. Wang E, Batey A, Struble C, Musci T, Song K, Oliphant A. Gestational age and maternal weight effects on fetal cell-free DNA in maternal plasma. Prenat Diagn 2013; 33: 662-666.

130. Canick JA, Palomaki GE, Kloza EM, Lambert-Messerlian GM, Haddow JE. The impact of maternal plasma DNA fetal fraction on next generation sequencing tests for common fetal aneuploidies. Prenat Diagn 2013; 33: 667-674.

131. Choi H, Lau TK, Jiang FM, Chan MK, Zhang HY, Lo PS, et al. Fetal aneuploidy screening by maternal plasma DNA sequencing: 'false positive' due to confined placental mosaicism. Prenat Diagn 2013; 33: 198-200.

132. Grati FR, Malvestiti F, Ferreira JC, Bajaj K, Gaetani E, Agrati C, et al. Fetoplacental mosaicism: potential implications for false-positive and false-negative noninvasive prenatal screening results. Genet Med 2014; 16: 620-624.

133. Futch T, Spinosa J, Bhatt S, de Feo E, Rava RP, Sehnert AJ. Initial clinical laboratory experience in noninvasive prenatal testing for fetal aneuploidy from maternal plasma DNA samples. Prenat Diagn 2013; 33: 569-574.

134. Snyder MW, Gammill HS, Shendure J. Copy-Number Variation and False Positive Results of Prenatal Screening. N Engl J Med 2015; 373: 2585.

135. Wang $Y$, Chen $Y$, Tian F, Zhang J, Song $Z, W u$, et al. Maternal mosaicism is a significant contributor to discordant sex chromosomal aneuploidies associated with noninvasive prenatal testing. Clin Chem 2014; 60: 251-259.

136. Osborne CM, Hardisty E, Devers $P$, Kaiser-Rogers $K$, Hayden MA, Goodnight W, et al. Discordant noninvasive prenatal testing results in a patient subsequently diagnosed with metastatic disease. Prenat Diagn 2013; 33: 609-611.

137. Bianchi DW, Chudova D, Sehnert AJ, Bhatt S, Murray K, Prosen TL, et al. Noninvasive Prenatal Testing and Incidental Detection of Occult Maternal Malignancies. JAMA 2015; 314: 162-169.

\begin{abstract}
The prenatal diagnosis and screening, as well as the diagnosis and monitoring of diseases in various medicine fields, is now made more easily thanks to the cell free DNA present in plasma. This DNA represents a small part of the genetic information of a particular tissue or, in the case of pregnant women, a proportion of the fetal DNA. In oncology, for example, given the heterogeneity of cancer, the application of cell free DNA has been difficult to implement since there are only some specific tumoral biomarkers for research use. Methodologies such as real-time polymerase chain reaction (PCR) show a high sensitivity to detect mutations that allow a correct diagnosis and treatment of fetal or tumoral diseases, at the same time reducing costs. This represents a great opportunity to continue the research and developmental processes of tests that allow its implementation in the clinical area in the near future, with reliable results in diagnosis and treatment of diseases without compromising the patient's integrity.
\end{abstract}

Key words: Cell-free DNA, liquid biopsy, prenatal diagnosis, cancer, aneuploidy. 